\title{
FEATURE On-farm soil health evaluations: Challenges and opportunities
}

\author{
Douglas L. Karlen, Nicholas J. Goeser, Kristen S. Veum, and Matt A. Yost
}

nterest in soil health (or soil quality) by producers, conservationists, environmentalists, agricultural scientists, policy makers, and many other groups has increased exponentially during the past five years. Yet questions remain: can soil health be measured at the field or farm scale, and can that data be used to improve land management decisions and thus help protect, conserve, and restore our fragile soil resources? Our opinion, based on three years of experience through the Soil Health Partnership (SHP), is that the answer to both of these questions is a resounding yes! Recognizing that several other public and private groups are now expressing interest in assessing soil health, our goals are to (1) summarize several of the SHP lessons learned during the past three years, (2) provide guidelines for future on-farm soil health studies, and (3) share some of our preliminary soil health assessment findings.

\section{EVOLUTION OF THE SOIL HEALTH PARTNERSHIP}

The SHP is a farmer-led initiative of the National Corn Growers Association developed in 2014 with financial and technical support from Monsanto, the USDA Natural Resources Conservation Service (NRCS), United Soybean Board, Walton Family Foundation, Midwest Row Crop Collaborative, Environmental Defense Fund, and Nature Conservancy. The SHP defines soil health as the continued capacity of a soil to function as a vital living ecosystem that sustains plants, animals, and humans. The ultimate SHP goal is to "measure and communicate economic and environmental benefits

Douglas L. Karlen is a research soil scientist with the USDA Agricultural Research Service at the National Laboratory for Agriculture and the Environment (NLAE) in Ames, lowa. Nicholas J. Goeser is the Director of the Soil Health Partnership in Chesterfield, Missouri. Kristen S. Veum and Matt A. Yost are research soil scientists with the USDA Agricultural Research Service Cropping Systems and Water Quality Research Unit in Columbia, Missouri. of different soil management strategies, and to provide a set of regionally specific, data-driven recommendations that farmers can use to improve the productivity and sustainability of their farms" (SHP 2016). More information about the SHP mission and primary goals can be found on the SHP website (http://soilhealthpartnership.org/goals.html).

\section{A SOIL HEALTH (SOIL QUALITY) FLASHBACK}

Soil health/quality is a concept that simply defined is "the capacity of a soil to function" (Karlen et al. 1997). It was introduced to the scientific community more than 40 years ago (Warkentin and Fletcher 1977). Throughout the 1990s, research and technology transfer efforts focused on the concept were aggressively led by both the USDA Agricultural Research Service and NRCS. Interagency, university, and privatesector collaboration fostered by the original NRCS Soil Health Institute resulted in many accomplishments during that era. They included (1) publication of several peer-reviewed journal articles and book chapters, (2) construction of state-specific soil health scorecards, (3) development and commercialization of soil health test kits, and (4) preparation of numerous fact sheets and other materials. Federal, state, and private sector efforts on soil health per se waned during the early 2000s, but during the last five years, several factors, including a renewed public awareness of earth's rapidly increasing population, greater affluence and desires for higher protein diets around the world, the United Nations's designation of 2015 as the "International Year of Soils," proclamation of 2015 to 2024 as the "International Decade of Soils" by the International Union of Soil Scientists, and recognition that global soil resources are continuing to be degraded by erosion and loss of soil organic matter (Karlen and Rice 2015), have fueled a resurgence in soil health activities.

In response to the increased awareness of the fragility of our global soil resources, several public and private organization actions have been undertaken. For example, the Farm Foundation NFP and Samuel Roberts Noble Foundation collaborated to initiate the Soil Renaissance, which according to their strategic plan (Conklin and Buckner 2015) was designed to focus on the role of soil health in vibrant, profitable, and sustainable natural resource systems. The Soil Renaissance goals included advancing soil health to make it the cornerstone of land use management decisions and striving to meet the challenge of feeding 9 billion people by 2050 . Ultimately, the Soil Renaissance led to formation of a new Soil Health Institute, whose mission is to "safeguard and enhance the vitality and productivity of soil through scientific research and advancement." Also during the past five years, the NRCS formed the Soil Health Division to complement the Soil Science Division and Ecological Sciences Division in promoting care and conservation of US soil resources. Many of the information resources developed by the original NRCS Soil Health Institute were updated, and new efforts, including a rigorous review and testing of soil quality indicators and assessment protocols, are being initiated. Furthermore, the 2014 Farm Bill created the Foundation for Food and Agriculture Research, which has identified "Healthy Soils, Thriving Farms" as one of its challenge areas. Most recently, increasing awareness of how fragile and important our nation's soil resources are for solving many rural economic, environmental, and social problems stimulated development of a Soil Science Interagency Working Group. This group was tasked with creating a Federal Strategic Plan entitled "The State and Future of US Soils-Framework for a Federal Strategic Plan for Soil Science." The vision and mission for this interagency assessment are "a future in which the Nation manages its soils to support healthy ecosystems, vibrant communities, and a secure world," and "establishment of a whole-of-government approach for interagency coordination and collaboration on soil research, conservation, and restoration priorities," respectively (SSIWG 2016). Many of these groups have 
identified conducting national soil health assessments as important initial activities, but to date, none have developed an infrastructure to carry out such assessments.

Recognizing that awareness of the challenges encountered in developing regional soil health assessments for the SHP could be useful for leaders of the Soil Health Institute, NRCS Divisions, Foundation for Food and Agriculture Research, and Soil Science Interagency Working Group, as well as numerous nongovernment organization, private sector, and state soil health coordinators, our objective for this report is to share some of the key lessons learned during the first three years of SHP activities.

\section{LESSONS LEARNED THROUGH THE SOIL HEALTH PARTNERSHIP}

During the first three years, the SHP has developed an on-farm research and demonstration network involving 65 farms and four community colleges in Illinois, Indiana, Iowa, Minnesota, Missouri, Nebraska, Ohio, North Dakota, and Wisconsin. Guided by a science advisory council (SAC), the SHP has garnered sufficient financial support to plan for at least a 10-year study period; identified critical, farmer-based questions that need to be answered regarding the concept of soil health/quality; developed appropriate on-farm experimental designs; organized economic, soil health indicator, and integration teams; and developed a technical support staff that can assist producers with designing, sampling, and interpreting the research results for their individual farming operations.

Several lessons have already been learned through the SHP initiative. First and foremost, on-farm research will neither be inexpensive nor will it be as precise and controlled as most research scientists would like. On-farm studies are always vulnerable to the necessary adaptation and vagaries of production agriculture. Not only will whatever can go wrong go wrong (e.g., weather disasters, unexpected herbicide problems, inaccurate fertilizer and lime applications, unintended cattle grazing, etc.), but there is also a high probability that the cooperating producer will be forced to make management changes with little or no time for discussion with researchers to determine how the change will impact the experiment. On-farm research can also be costly because in addition to providing sample collection, analysis, and interpretation by technically trained individuals, most effective studies will also require a stipend and compensation should the experimental treatments substantially reduce crop yields when compared to the producer's current management practices or to compensate for time commitments to the research program. It is also important to recognize that producers are going to be most interested in economics and the operational requirements (i.e., cost) associated with the treatments, and as a result, they are often going to want to make annual or even more frequent modifications to the experimental design to accommodate the numerous factors they are managing.

A second important lesson is that an on-farm research network such as that being developed by the SHP will require a dedicated, multiperson infrastructure. This will include field managers who serve as "front line" contacts with the farmers participating in the project. An operations and/or data manager will also be needed to serve as a conduit between the field managers, SAC, and those persons who are directing and funding the research.

\section{Figure 1}

Producer field days, especially those with soil pits, have proven an effective way for the Soil Health Partnership to increase awareness of soil health indicators and effects of improved management practices.

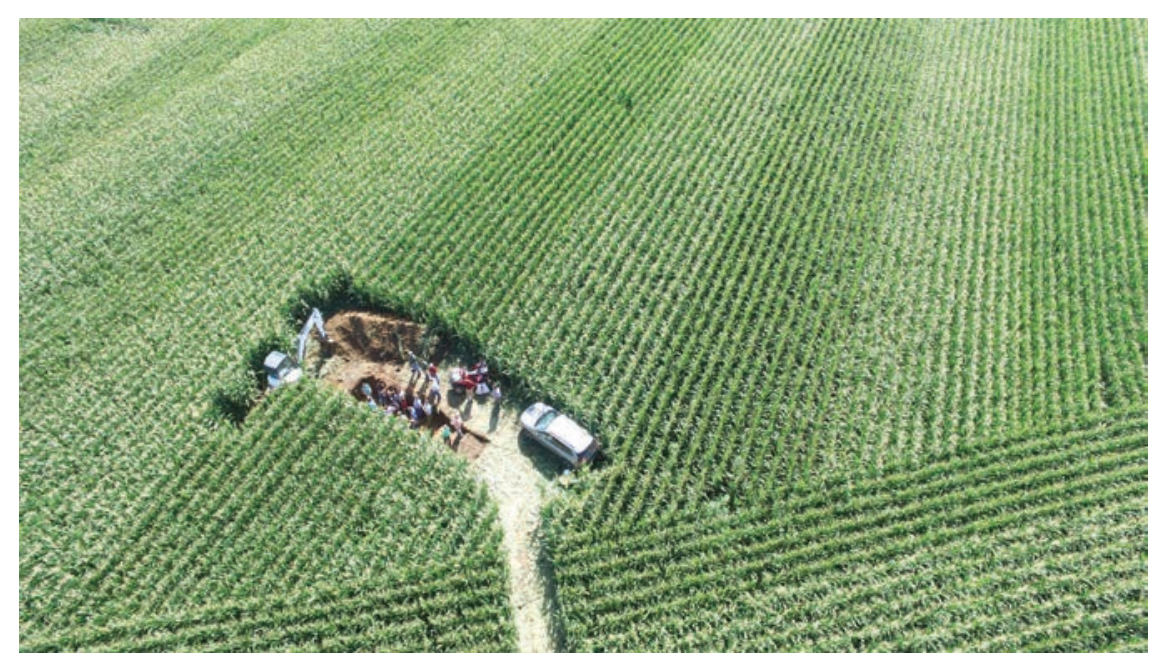

Financial and human resources dedicated to projects such as the SHP must be sufficient to support at least one field manager for every 15 farm locations. Field managers are essential liaisons to the producers who are doing their best to integrate a research project into their already complex and time-consuming farm management operations. Tasks that field managers will be called upon to handle include (1) helping producers identify appropriate field sites; (2) laying out replicated treatment strips that meet both the statistical design and production requirements associated with the treatments; (3) coordinating soil, plant, yield, and other sampling events; (4) ensuring that samples are submitted for analysis in a timely manner and tracked; (5) interpreting the analytical results to the producers and providing them with rapid feedback regarding the implications; (6) ensuring management practice (i.e., metadata) information is collected, recorded, and submitted to the analytical teams in a timely manner; (7) working (where appropriate) with the cooperating farmer's agronomist to relay research findings and solicit feedback; (8) managing collaborative and other political networks within their assigned territories, and (9) coordinating producer field days and other farmer engagement events (figure 1). 
A third lesson is that having a diverse SAC is crucial to ensure scientific rigor and valid experimental questions are being answered. Inevitably, producers will want to "test" several different factors (e.g., reduced tillage, advanced nutrient management, cover crops, soil type, etc.) and may even be willing to commit several adjacent fields to the study. The SAC can help project leaders, field managers, and producers develop a balance that results in scientifically comparable data without limiting the creativity and innovation upon which collaboration is often built. A well-qualified SAC can provide (1) guidance with regard to appropriate soil health indicator selection; (2) valid experimental designs and treatments that can be effectively implemented and compared at the field and/or farm scale; and (3) unbiased statistical and/or economic analysis of the data. A well-respected science advisory team also lends credibility to the overall project and can be influential in sustaining current funding sources and attracting new ones to sustain the treatment comparisons needed to quantify long-term soil management effects.

A fourth important lesson, especially for those investing in on-farm research, is that the implementation phase, for multistate projects in particular, will be much slower than expected. This is especially true for new projects that require recruitment of an operations manager, field managers, and producers, as well as selection of sites, development and implementation of appropriate experimental designs, collection of baseline samples, establishment of analytical services, data management, and other logistical steps. In the first year of this project, only $60 \%$ of sites collected and submitted data. In contrast, with more complete planning and a project support staff in place, $94 \%$ to $98 \%$ of all sites submitted data in the second and third years.

The final lesson was that multistate, on-farm projects must have a well-developed, efficient, and effective communication infrastructure. Questions must be responded to quickly, and answers must flow efficiently among producers, field managers, project leaders, technical advisors, and funding sources. Due to the participatory nature of on-farm research, the project infrastructure, including data collection, storage, processing, and interpretation across sites should be incorporated into the overall project plan and understood by all parties. Also, to facilitate project outreach and communication among participants as well as the public, the initial SHP experience has confirmed the importance of developing a communication strategy that includes multiple types of information sources (i.e., videos, pictures, tweets, and other forms of social media) that utilize a variety of effective platforms and are specifically targeted and delivered to different audiences in a timely manner. It is also important to track effectiveness of the outreach using media metrics such as earned media impressions and the number of website sessions.

\section{SO, CAN SOIL HEALTH BE MEASURED AT THE FIELD SCALE?}

Three years after initiation of the SHP, we remain confident that soil health can be measured at the field scale and that the results can be used to further improve soil management decisions. Although several cooperators wanted to compare more complex soil health treatments, the SAC strongly urged project managers to simply focus SHP studies on cover crop effects at each participating site, with limited options to collect pilot data to address nutrient management, tillage, and other potential research hypotheses. Even with the limitation on cover crops, many different plant species were selected by the producers. Most focused on small grains (e.g., oat [Avena sativa] or rye [Secale cereal]), but tillage radish (Raphanus sativus; figure 2) and an occasional legume (e.g., hairy vetch [Vicia villosa ssp]) were also grown alone or in various mixtures. The SHP is not unique in its focus on cover crops, since many other multistate research collaborations, such as the Midwest Cover Crops Council (http://mccc.msu.edu/), have documented positive effects of several cover crop species on soil health indicators. What is unique about the SHP is that it is a farmer-driven, on-farm initiative. Therefore, collection of SHP data is providing an opportunity to quantify on working farms many soil health benefits that have been attributed to cover crops. These include but are not limited to

\section{Figure 2}

A Soil Health Partnership farmer cooperator showcasing his radish cover crop.

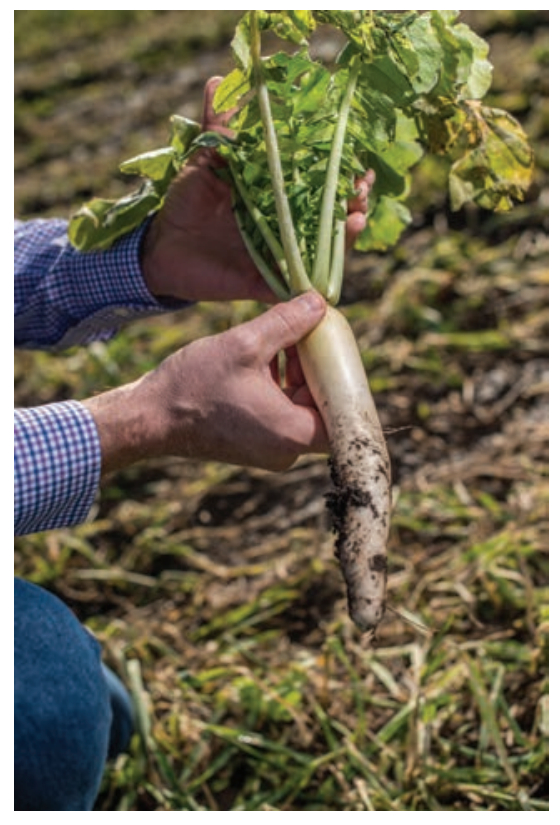

(1) penetration of roots between soil aggregates and peds that can disrupt compacted areas and gradually improve soil structure; (2) provision of root exudates and other carbon (C) sources that can serve as food for earthworms and other soil macro- and microfauna; (3) reduction in intensity and frequency of tillage in order to accommodate planting and growing cover crops systems; (4) decreased soil loss through wind and water erosion by keeping the ground covered for longer periods of time; and (5) capture of nutrients thus preventing their loss through runoff and/or leaching.

For several logistical reasons, including ongoing but limited submission of metadata, only preliminary assessments and summaries can be made at this time. However, the initial results indicate that the Soil Management Assessment Framework (SMAF) developed by Andrews et al. (2004) and the Comprehensive Assessment of Soil Health (CASH) that evolved from the SMAF (Fine et al. 2017) will be useful for helping producers quantify the soil health effects of growing cover crops and reducing tillage intensity at the field scale. Fortunately, both frameworks have been incorporated into the SHP assessment protocol and both frameworks function 
by transforming laboratory-measured chemical, physical, and biological data into ratings that are adjusted based on site-specific information including inherent soil characteristics.

We are confident in this soil health assessment approach because CASH has been used by the Cornell University Soil Health Lab as a commercial-scale, userfriendly soil health test (Fine et al. 2017) and the SMAF has been used to quantify impacts of several soil management experiments in the United States (Karlen et al. 2011, 2015; Veum et al. 2014, 2015) and for tillage or land use change evaluations in other countries (Imaz et al. 2010; Cherubin et al. 2016). Those studies have shown that trends in soil health are linked to management at a broad level (e.g., perennial versus annual cropping systems), and that soil health within these agroecosystem types is further dictated by practices such as biomass removal, soil disturbance, and crop rotation/diversity (figure 3).

For this initial SHP analysis, the SMAF assessment utilized soil organic C (converted from organic matter), wet aggregate stability, phosphorus $(\mathrm{P})$, potassium $(\mathrm{K})$, and water $\mathrm{pH}$ measurement data. The $\mathrm{CASH}$ analysis included organic matter, active C, available water capacity, wet aggregate stability, soil respiration, soil protein, $\mathrm{P}, \mathrm{K}$, water $\mathrm{pH}$, and minor elements. Both assessment frameworks calculate ratings for individual indicators that are integrated into a nonweighted average or "overall" score. The SMAF indicator ratings can also be grouped into biological, physical, or chemical categories to explore how a specific soil is functioning relative to its inherent potential (Andrews et al. 2004).

Among the most notable findings in the preliminary SHP analysis was the overarching influence of inherent soil properties on keystone soil health indicators, such as organic matter, where a clear trend with respect to particle size distribution (i.e., soil texture) was evident (figure 4). Similar trends were observed with several other soil health indicators, providing a strong reminder that accounting for site-specific characteristics, and soil texture in particular, is crucial for a meaningful soil health assessment. It is known that clay content and clay mineralogy are controlling fac-

\section{Figure 3}

Continuum of soil health based on Veum et al. (2014, 2015). CRP is Conservation Reserve Program.

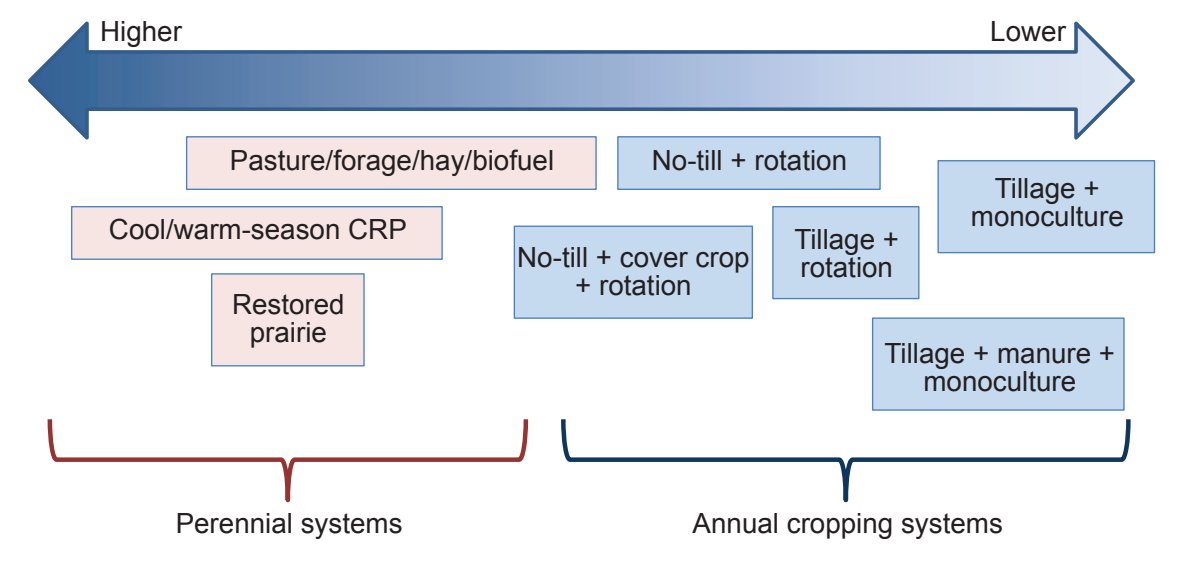

\section{Figure 4}

Measured relationships between soil texture category $(n=645)$ and mean soil organic matter content (with standard error of the mean bars) within the 0 to $15 \mathrm{~cm}$ layer of Soil Health Partnership sites from seven different states.

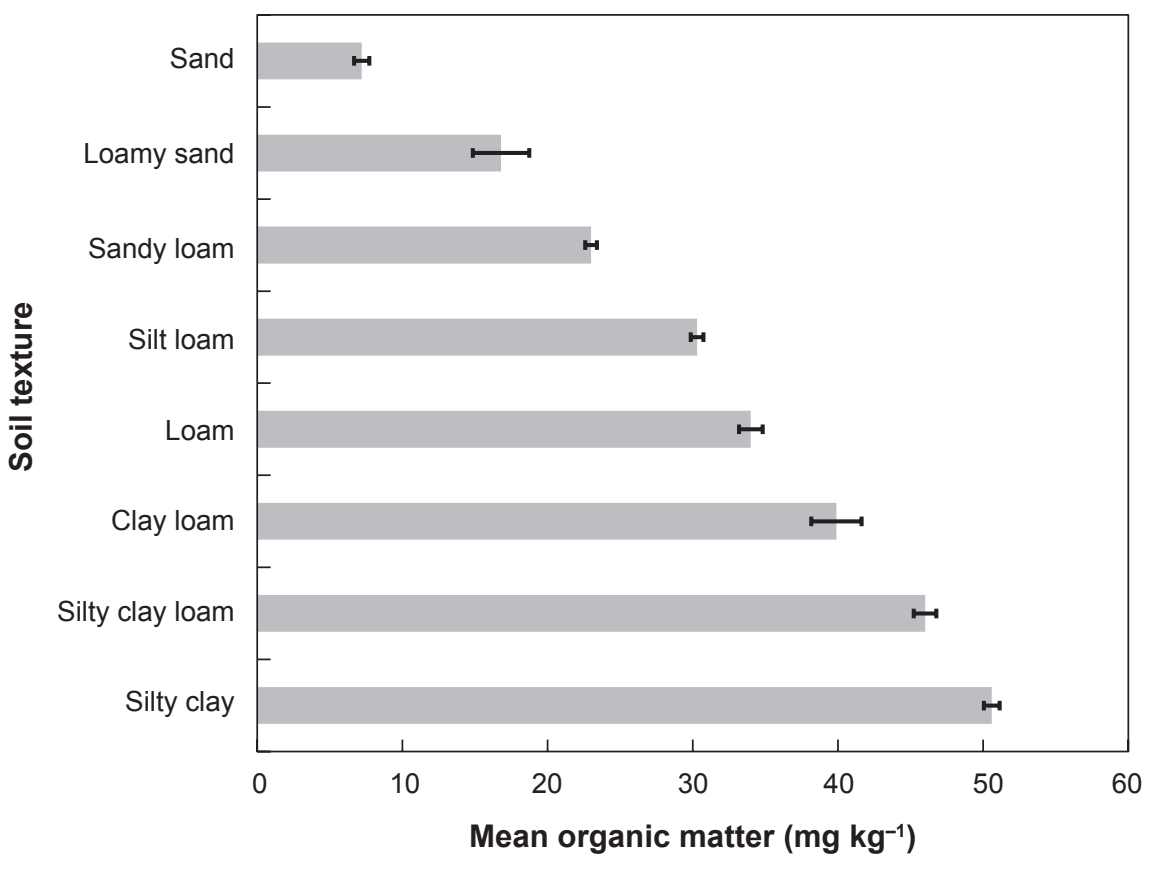

tors in numerous soil physical, chemical, and biological attributes of soil, such as cation exchange capacity, soil aggregation, and retention of organic matter. The developers of both indices understood the importance of inherent soil characteristics in soil health assessment-for example, an Ultisol does not have the same potential as a Mollisol to retain organic matter-and SMAF rating curves were developed to account for these differences up front. The SHP data analysis confirms and illustrates this concept very well by representing a wide range of soils from across nine Midwestern states.

Broad relationships among soil health indicators and other soil properties were also explored. Moderate to strong positive relationships with clay content were found for organic matter $\left(R^{2}=0.56\right), \mathrm{K}\left(R^{2}\right.$ 
$=0.38)$, and magnesium $\left(\mathrm{Mg}, R^{2}=0.62\right)$. Available water content was positively correlated with silt content $\left(R^{2}=0.46\right)$ and negatively correlated with sand content $\left(R^{2}=0.56\right)$. Active $\mathrm{C}$ was highly correlated with organic matter $\left(R^{2}=0.71\right)$, and wet aggregate stability was positively correlated with organic matter, $\mathrm{K}$, and $\mathrm{Mg}\left(R^{2}=0.30\right.$, 0.29 , and 0.40 , respectively). In contrast, soil respiration and soil protein measurements were only weakly correlated $\left(R^{2}<0.15\right.$ and 0.27 , respectively) with other soil properties or soil health indicators.

The preliminary SHP analysis also involved exploring relationships among soil health indicators and ratings from the SMAF and CASH assessments ( $\mathrm{n}=471$ and 411, respectively). Across all results, less than $2 \%$ of soils were identified as having very serious constraints (rating $<50 \%$ ), and 95\% of soils demonstrated constraints in at least one soil health category. In general, the SMAF rated soils slightly higher than CASH. Given that CASH was modeled after the SMAF assessment, it was not surprising that ratings between the two assessments were highly correlated $\left(R^{2}=0.53, n=264\right)$ across all sites (figure 5), despite the fact that the assessments included different suites of indicators. A noteworthy exception to this was one SHP site that exhibited excessive levels of soil $\mathrm{P}$ ranging from 236 to $428 \mathrm{mg} \mathrm{kg}^{-1}$. The SMAF is designed to reduce $\mathrm{P}$ ratings to account for the increased environmental risk associated with $\mathrm{P}$ levels in excess of crop requirements. On a broad level, soil health assessment is intended to assess soil functions that relate to multiple important ecosystem services, including environmental protection (e.g., water quality). Therefore, crop productivity, although a critical agroecosystem function, is not the sole driver for a valid soil health assessment. The ratings from this site illustrated how the SMAF effectively identifies sites at increased environmental risk.

One common concern of producers and others interested in soil health assessment is the reproducibility of soil health measurements across laboratories (e.g., service or commercial laboratories). In this analysis, we found excellent correlation in organic matter measurements between two laboratories $\left(R^{2}=0.77, n=645\right)$.

\section{Figure 5}

Scatterplot of Soil Management Assessment Framework (SMAF) ratings and Comprehensive Assessment of Soil Health (CASH) ratings for 264 soil samples collected from on-farm studies associated with the Soil Health Partnership in nine midwestern US states.

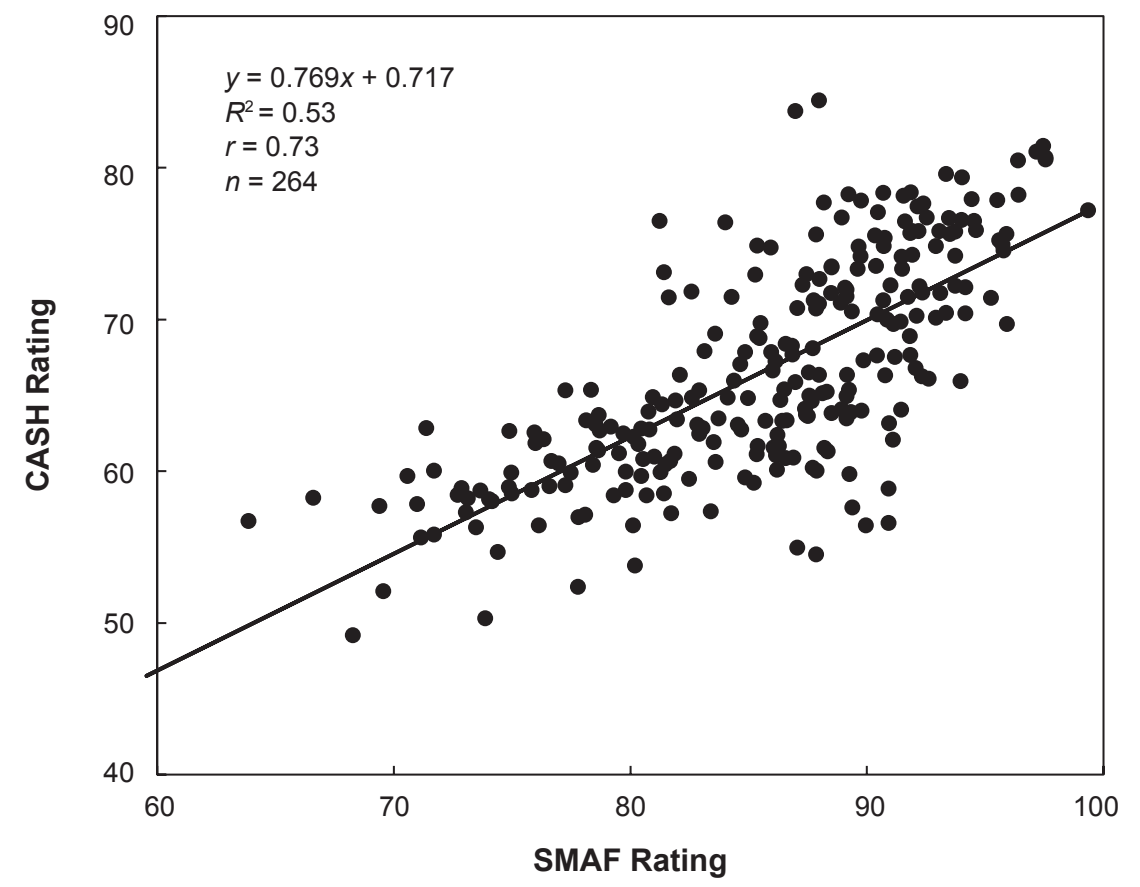

In contrast, soil respiration and nutrient measurements between labs were not well correlated mainly because two different soil respiration incubation times (24 hours and 96 hours) and two distinctly different nutrient extraction methods (modified Morgan and Mehlich 3) were used.

At the field scale, nonstatistical comparisons of soil health indicators and ratings were made at select SHP sites where metadata were available. Use of cover crops appears promising, but the number of sites with complete metadata and measured response data is too limited to make any valid statements at this time.

\section{SUMMARY AND CONCLUSIONS}

In only three years, the SHP has become a successful regional collaborative effort that brought together funding from sources that only a few years ago would have been considered to be totally incompatible. This alone is a very strong indicator of societal recognition that our soil resources are indeed being threatened and/or degraded at an unsustainable rate. Soil health concepts are being embraced by farmers, conservationists, research scientists, and policy makers around the world. Many challenges remain, but soil health can certainly be assessed at the field scale and the concept is no longer purely academic. Rather, it is currently an important strategy to ensure that the expanding global demand for food, feed, fiber, and fuel can be met while maintaining and enhancing other important functions and ecosystem services provided by the soil.

\section{REFERENCES}

Andrews, S.S., D.L. Karlen, and C.A. Cambardella. 2004. The soil management assessment framework: A quantitative evaluation using case studies. Soil Science Society of America Journal 68:1945-1962.

Cherubin, M.R., D.L. Karlen, A.L.C. Franco, C.E.P. Cerri, C.A. Tormena, and C.C. Cerri. 2016. A Soil Management Assessment Framework (SMAF) evaluation of Brazilian sugarcane expansion on soil quality. Soil Science Society of America Journal 80:215-226.

Conklin, N., and W. Buckner. 2015. Soil Renaissance Strategic Plan.Ardmore, OK: Farm Foundation NFP and Noble Foundation. www.soilrenaissance.org. 
Fine, A.K., H.M. van Es, and R.R. Schindelbeck. 2017. Statistics, scoring functions and regional analysis of a comprehensive soil health database. Soil Science Society of America Journal, forthcoming.

Imaz, M.J., I. Virto, P. Bescansa, A. Enrique, O. Fernandez-Ugalde, and D.L. Karlen. 2010. Soil quality indicator response to tillage and residue management on semi-arid Mediterranean cropland. Soil and Tillage Research 107:17-25.

Karlen, D.L., M.J. Mausbach, J.W. Doran, R.G. Cline, R.F.Harris, and G.E. Schuman. 1997. Soil quality:A concept, definition, and framework for evaluation. Soil Science Society of America Journal 61:4-10.

Karlen, D.L., and C.W. Rice. 2015. Soil degradation: Will humankind ever learn? Sustainability 7:12490-12501.

Karlen, D.L., D.E. Stott, C.A. Cambardella, R.J. Kremer, K.W. King, and G.W. McCarty. 2015. Surface soil quality in five Midwestern cropland Conservation Effects Assessment Project watersheds. Journal Soil and Water Conservation 69(5):393-401, doi:10.2489/jswc.69.5.393.

Karlen, D.L., G.E. Varvel, J.M.F. Johnson, J.M. Baker, S.L. Osborne, J.M. Novak, P.R. Adler, G.W. Roth, and S.J. Birrell. 2011. Monitoring soil quality to assess the sustainability of harvesting corn stover. Agronomy Journal 103:288-295.

SHP (Soil Health Partnership). 2016. Our Goals. Chesterfield, MO: Soil Health Partnership. http://soilhealthpartnership.org/goals.html.
SSIWG (Soil Science Interagency Working Group). 2016. The State and Future of US Soils_-Framework for a Federal Strategic Plan for Soil Science. Washington, DC: National Science and Technology Council; Committee on Environment, Natural Resources, and Sustainability; Subcommittee on Ecological Systems; Soil Science Interagency Working Group. https://obamawhitehouse.archives.gov/ sites/default/files/microsites/ostp/ssiwg_framework_december_2016.pdf.

Veum, K.S., K.W. Goyne, R.J. Kremer, R.J. Miles, and K.A. Sudduth. 2014. Biological indicators of soil quality and soil organic matter characteristics in an agricultural management continuum. Biogeochemistry 17:81-99.

Veum, K.S., R.J.Kremer, K.A.Sudduth, N.R. Kitchen, R.N. Lerch, C. Baffaut, D.E. Stott, D.L. Karlen, and E.J. Sadler. 2015. Conservation effects on soil quality indicators in the Missouri Salt River Basin. Journal of Soil and Water Conservation 70(4):232-246, doi:10.2489/jswc.70.4.232.

Warkentin, B.P., and H.F. Fletcher. 1977. Soil quality for intensive agriculture. In Intensive agriculture society of science, soil and manure. Proceedings of the International Seminar on Soil Environment and Fertilizer Management, p. 594-598. Tokyo, Japan: National Institute of Agricultural Science. 